\title{
Characterising the Use of Mathematical Knowledge in Boundary-Crossing Situations at Work
}

\author{
Phillip Kent, Richard Noss, David Guile, Celia Hoyles \& Arthur Bakker \\ Institute of Education, University of London \\ (25 May 2006, final version for submission to Mind, Culture, and Activity)
}

\begin{abstract}
The first aim of this paper is to present a characterisation of techno-mathematical literacies needed for effective practice in modern, technology-rich workplaces that are both highly automated and increasingly focused on flexible response to customer needs. The second aim is to introduce an epistemological dimension to activity theory, specifically to the notions of boundary object and boundary crossing. In this paper we draw on ethnographic research in a pensions company and focus on data derived from detailed analysis of the diverse perspectives that exist with respect to one symbolic artefact, the annual pension statement. This statement is designed to facilitate boundary crossing between company and customers. Our study showed that the statement routinely failed in this communicative role, largely due to the invisible factors of the mathematical-financial models underlying the statement that are not made visible to customers, or to the customer enquiry team whose task is to communicate with customers. By focusing on this artefact in boundary-crossing situations, we identify and elaborate the nature of the techno-mathematical knowledge required for effective communication between different communities in one financial services workplace, and suggest the implications of our findings for workplaces more generally.
\end{abstract}

\section{Introduction: Techno-mathematical Literacies}

This paper presents findings from our ongoing research aimed at characterising the use and development of mathematical knowledge at work. We are concerned with how the mathematical aspects of workplace artefacts (particularly computer inputs and outputs, and other documents containing symbolically-expressed information) are understood by individuals and teams, and how these understandings are communicated. Our focus is on data drawn from a range of industrial and commercial workplaces, with a principle concern in this paper on data from a large pensions company.

Over the last two decades, the nature of mathematical knowledge required in workplaces has been influenced by two significant changes. The first change has been a dramatic increase in the deployment of information technologies as a pervasive, mediating presence within workplace practices (Felstead, Gallie, \& Green, 2002; Kim, 2002). An early study of "computerisation" of manufacturing and service industries by Zuboff (1988) describes the dual potential of IT to automate and to informate; that is, on the one hand the potential of technology to replace human work, and on the other hand its potential to inform human work by making information more accessible and usable. In 
order to be "informated" individuals are increasingly forced to ask questions about the data generated by the computerisation of the work process, for example, "What is happening?" and "What does this mean?" (ibid, p. 196). Answering the type of questions that arise from working in a symbolic medium, Zuboff argues, raises issues of communication and collaboration in the workplace, and accomplishing work comes to depend more upon a capacity for "theoretical" or "system thinking" in which workers are able to identify what an automated IT system is doing and what follows from it, rather than simply upon acting out a process based on know-how derived from experience (cf. Guile, 2006).

The second significant change in workplaces is the shift from focusing largely on production of identical mass-produced outputs to one prioritising response to customer requirements on a more individual basis (Victor \& Boynton, 1998). In the financial services context that we will describe later, this shift is connected to a business perception that competitive advantage comes from offering customers a far greater degree of flexible communication. Taken together, these two changes have impacted on the nature of the mathematical skills required in modern workplaces. For example employees at most levels in any company need to understand some elements of what is behind the interface of the IT system, so they can communicate with others in different parts of the workplace, and with customers who are demanding more information and more transparency. Thus, new work practices increasingly involve quantitative or symbolic data processed by information technology, as part of the interactions between employees, and between employees and customers. We seek to characterise and develop the forms of mathematical thinking that enable these data to be interpreted and their meanings negotiated.

Mathematics is widely considered a problematic subject in workplaces and employers have for a long time been reporting "skills deficits". National governments in many countries have put forward waves of policy and curriculum innovations to address the problem in the school and vocational education system as well as in lifelong learning (Coben, 2003; Coben, in press; Fitzsimons, Coben, \& O’Donaghue, 2003). The debate has been focused on the notion of "numeracy" (Fitzsimons, 2002; for a critique of "numeracy" see Noss, 1998) and, more recently in the UK, on the specification of core functional mathematical skills (Wake, 2005). In our own research on mathematics in workplaces over more than a decade, we have studied the practices of professional, technical and intermediate grade workers in a wide range of service and manufacturing industries, such as finance, nursing, commercial airlines, civil engineering, pharmaceutical manufacturing, tourism, food processing and packaging (Hoyles, Wolf, Molyneux-Hodgson, \& Kent, 2002; Kent \& Noss, 2000; Noss \& Hoyles, 1996a, 1996b).

This work has shown the need to characterise more precisely the nature of mathematics used in the workplace, and leads us to argue that much of the discussion around "skills gaps" and the non-transferability of school mathematics misses the essential characteristics of the knowledge required in technology-mediated work. As workplaces have become more and more organised around IT systems, mathematical processes have tended to become less visible - the mathematics becomes embedded within the IT models. This means that there has been a shift in requirement from fluency in doing explicit pen-and-paper calculations, to fluency in using and interpreting outputs from IT 
systems and software, alongside some appreciation of the mathematical models deployed within them, in order to informate workplace judgements and decision-making.

Thus, rather than traditional notions of numerical skill and competence, we find more relevance in the concept of "mathematical literacy" (see Coben, 2003, p. 15, for a review of the literature on this concept). For example, the OECD's Programme of International Student Assessment (PISA) defines it as follows:

Mathematical literacy is an individual's capacity to identify and understand the role that mathematics plays in the world, to make well-founded judgements and to use and engage with mathematics in ways that meet the needs of that individual's life as a constructive, concerned and reflective citizen. (OECD, 2003, p. 24).

However, the developments discussed above indicate that a specific characterisation of mathematical literacy is required that takes account of the character of the workplace in which IT is pervasive. We have therefore adopted the term "techno-mathematical literacies": the prefix, "techno", emphasising the mediation of mathematical knowledge by technology, and the plural form of "literacies" pointing to the breadth of knowledge required in the context of contemporary work. By using the term "literacies" we intend also to stress the importance of engagement that goes beyond symbol manipulation to an appreciation of how the same symbols are constitutive of different meanings across different contexts.

In this paper, we present evidence of the techno-mathematical literacies needed in the financial services sector. Our evidence is drawn from a study in a pensions company, but we are confident of its generalisability as we have noted similar needs in other types of financial services companies, such as banks and mortgage companies.

\section{Boundary objects and boundary crossing}

To assist in identifying the nature of techno-mathematical literacies, we have employed activity theory as a "theoretical lens" (Russell, 2002) to analyse workplaces as being characterised by their own object of activity (i.e., the motive or purpose of work), mediated by artefacts and located in a context characterised by a specific division of labour, sets of rules of discourse and inter-related workplace communities (e.g., Engeström, 2001; Kaptelinin \& Miettinen, 2005; Kuutti, 1996). From this perspective, it is evident that employees and managers have different engagements with the object of activity, use diverse tools (or the same tools for different purposes) and follow distinct rules, in their attempt to realise that object. Hence any attempt to understand what employees are doing simply in terms of lists of generic, context-independent competencies $^{1}$, fails to take account of tool mediation and how technologies fundamentally alter the activity system of the workplace, and - above all - the knowledge required for the effective use of technology. By focusing on techno-mathematical literacies we intend to address this issue.

One of the merits of the literature on cultural-historical activity theory is that it has drawn attention to forms of learning and development that previously have not been well

\footnotetext{
${ }^{1}$ As Rothwell \& Lindholm (1999) observe, a typical approach is to define sets of competences and programmes to develop them in generic terms.
} 
described, such as horizontal learning (Engeström, 2001). Nonetheless, Guile and Young (2003, p.79) have argued that "the role of scientific concepts seems to have got lost in recent developments in activity theory with their stress on activities, context and horizontal development". Our research aims to restore some balance with respect to knowledge, while simultaneously taking into account recent insights derived from activity-theoretical approaches. Thus we use the concept of an activity system, not so much to characterise the mediated relationships between the object of activity, tools and communities in areas of work, but rather to help us focus on the role of technomathematical literacies.

As we have already suggested, the knowledge underlying the sites of technomathematical activity in an IT-based workplace is under the surface of the computer systems and software. We have found that the use of mathematics most readily becomes visible in activity when the artefacts in use involve the expression of mathematical symbols, and are used to communicate information between different communities. Such artefacts include graphs, tables, charts and diagrams. We are interested in how such artefacts might be employed to allow diverse groups of employees to achieve shared objects of activity.

The notion of boundary object (Star \& Griesemer, 1989) and its more recent elaboration in the activity theory literature (e.g., Tuomi-Gröhn \& Engeström, 2003) proves useful for this purpose. We note that the term "object" here is distinct from the idea of object as motive of activity: "Boundary objects are those objects that both inhabit several communities of practice and satisfy the informational requirements of each of them" (Bowker \& Star, 1999, p. 297). Star and Griesemer originally introduced this notion for analysing the heterogeneous nature of scientific practice. They describe how boundary objects in the form of specially-designed data-recording forms for collecting field information on insects helped both amateur naturalists and professional scientists, groups that often existed in tension and limited mutual understanding, to coordinate their perspectives of studying insects in the state of California.

The idea of a boundary object as a way to analyse the heterogeneous nature of the knowledge at play in workplaces has been further developed by Wenger (1998). He used the notion to describe the role of medical claim processing forms as boundary objects, helping to coordinate the different communities of practice involved in medical claims (the client and the different departments within a medical insurance company). He also suggests that not all objects are boundary objects, since not all objects help to coordinate the perspectives of different communities (ibid, p. 107). In information-driven industries such as financial services, an explicit goal for artefact design, as we shall see, is to produce artefacts that can serve as boundary objects.

Engeström $(1999,2001)$ employs a further notion of "boundary crossing" in his intervention methodology, the Change Laboratory (1999) or the Boundary Crossing Laboratory (2001). His aim with these interventions is to contribute to change in activity systems by transforming the object of activity. One example was the reorganisation of work in a city healthcare system, which led to a different patient record form for the handling of patients. In this case, the record form that emerged from the Laboratory, was named by Engeström as an instrument, but served as a boundary object in the sense of Star and Griesemer (1989). 
One common link between these various approaches is that boundary objects have an explicit role to facilitate boundary crossing between various communities, communicating across different perspectives and facilitating shared decision-making. In the following detailed workplace example, we will describe our own use of the notions of boundary object and boundary crossing. While this follows from the analysis above, it adds our specific concern, which is to make visible the epistemological role of symbolic boundary objects in situations in which people from different communities use common artefacts with the intention of communication. Specifically, we will ask under what circumstances these artefacts actually become boundary objects, and how they may facilitate effective communication between and within work teams and between work teams and customers.

\section{Methodological remarks}

The case study presented in this paper was gathered as part of the "Techno-mathematical Literacies in the Workplace" project ${ }^{2}$. Here we present a very brief overview of our methodology: for details see Hoyles, Bakker, Kent, \& Noss (8 January, 2006). The industry sectors covered in this research are Financial Services, Pharmaceuticals Manufacturing, Packaging and Automotive Manufacturing. In the first phase of the research, we have carried out ethnographic case studies in ten companies, three of which were in financial services, in order to identify the existence of and need for technomathematical literacies. Methods used included workshadowing and conducting interviews around symbolic artefacts. In the second research phase, we have carried out design experiments (cf. Cobb, Confrey, diSessa, Lehrer, \& Schauble, 2003) to support employees in developing the techno-mathematical literacies identified in the first phase, and to illuminate further their characteristics.

In the two research phases, we adopted three slightly different notions of boundary crossing, while retaining a common essence, namely that successful boundary crossing involves reaching some consensus as to the epistemological nature of the boundary object, which derives from the mathematical symbolism used or the mathematical structures underlying the object (invariably produced or mediated by technology). In the ethnographic phase, the main role of boundary crossing occurred as we learned about the mathematical and contextual reasoning that characterised communication around artefacts in use. The second form of boundary crossing (largely the focus of this paper) occurred as we analysed how the artefacts stood between community boundaries and how different views of the artefact were or were not coordinated. A third form of boundary crossing occurs where we design tools and activities with the purpose of developing employees' techno-mathematical literacies, through reconstructing the mathematical artefacts from workplace practice with the help of computer tools, and opening them up for exploration and discussion.

We should stress that in all these forms, boundary crossing takes place in two directions: we learn about the companies' practices by talking about the purposes of the artefacts, while employees begin to adopt our language of techno-mathematical literacies and

${ }^{2}$ Website: www.ioe.ac.uk/tlrp/technomaths 
develop a different awareness of the epistemological underpinning of the artefacts. Similarly, in the design experiments, we do not present ourselves as experts who are going to "train" employees in modelling or mathematical reasoning. Rather we collaborate with managers and workplace trainers to produce "learning opportunities" for employees and in so doing, open windows onto their perceptions of techno-mathematical ideas. This third form of boundary crossing is not the topic of the present paper; for general background see Noss and Hoyles (1996b); see also Bakker, Kent, Noss, Hoyles, \& Bhinder (2006); Hoyles et al. (8 January, 2006).

\section{The case of Lifetime Pensions Limited ${ }^{3}$}

The data that we present in this paper is derived from the following situation. A pensions company annually sends out pension statements to inform its customers about the current and projected values of their funds. However, we learned that the pension statement is not always understood by customers, nor is it always well-understood by customer service employees, who often find it difficult to answer technical queries from customers. In these cases, the statement clearly did not function as a boundary object, and we studied why this was the case, and what might be done about it. We report on the new artefacts created by the company to enrich the communicative potential of the pension statement, and the extent to which this aim is fulfilled. After a general description of the company, we focus our analysis on a characterisation of the techno-mathematical knowledge that needs to be mobilised by the company in order for customer queries about their pension statements to be answered more effectively.

\section{Background of the company}

Lifetime Pensions is a major UK provider of private pensions and investments, serving well over 1 million customers. This company, like many other UK providers, is currently in the process of major restructuring as it attempts to improve its operation by becoming more "customer-focused" (i.e., flexibly serving the needs of individual customers). This shift in operational rationale has been necessary for a number of reasons. Throughout the financial services industry, a long-standing orientation on production rather than customer focus has resulted in customer trust being seriously eroded, to a great extent due to alleged mis-selling of products (this has typically involved customers being sold products where the potential benefits are highlighted but the risks are underestimated). Moreover, as we were told by managers in this company, customers have in general become "more demanding".

Lifetime Pensions follows current models of UK organisation and distinguishes between communication with existing customers through the "front" and "back" office. The former largely consists of call centres for telephone communication and basic customer administration. The latter, which is the focus of our case study, largely manages the business of existing customers. Front and back office roles are generally not high-skill in terms of formal qualifications (for example, a university-level education would not be

\footnotetext{
${ }^{3}$ The company name has been anonymised and we have altered some non-essential details of its operations to ensure confidentiality.
} 
required). Elsewhere within the company there are high-skill technical administration departments (particularly for IT systems), and product development departments employing actuaries who are the central source of expertise about pensions. One of the issues that quickly emerged in our case study was the general remoteness and inaccessibility from the back office team of these financial and IT experts.

\section{The Enquiry Team}

We investigated several areas of the back office of Lifetime pensions, but came to focus on one team, the Enquiry Team. One reason for our interest in this team, whose primary purpose is to answer enquiries from customers about their pensions, was that we observed most clearly in this area of work the need for techno-mathematical literacies as part of the explanation process. In other areas (closing and paying-out policies, for example) the interaction with the customer is closely-prescribed with little if any need for personal communication. Pensions are complex financial products that customers find difficult to understand: hence the need for the Enquiry Team. The Enquiry Team consists of about 25 people. The majority of enquiries come by post (a few by telephone, fewer by email), and about $85 \%$ of the responses are also currently made by post, although this is changing, with an increased use of telephone conversations with customers, which are perceived as more "customer friendly". Our ethnography suggested that telephone conversations have a significantly different quality to letter-based communication, in terms of the breadth and flexibility of knowledge required and skill in communicating it. The Enquiry Team employee has to take ownership of the enquiry and make immediate responses, rather than relying on the distributed knowledge of the team that can be exploited in writing a letter.

The educational background of Enquiry Team members is, for the most part, a general level of school-leaving qualifications (typically at age 16), possibly enhanced by several years working in financial services before joining the company. In terms of specific mathematics qualification, the company requires only an average grade in the basic (age 16) school-leaving qualification. To prepare Enquiry Team members to deal with enquiries, internal training is provided, and an option is offered for employees to acquire external industry-standard qualifications (which even at advanced levels address very few financial-mathematical issues or calculations).

In the previous Enquiry Team operational structure, work was production-focused: individual employees had to process a certain number of pieces of work per day, that is move enquiries through the system, to some degree irrespective of the needs of customers. In the new, emerging structure, straightforward customer enquiries such as questions on specific management charges, should be resolved if possible immediately by telephone. This requires employees to work as a team, finding out in real time anything they do not know from colleagues (a form of "learning on demand", as expressed by the training manager), rather than passing the case on to someone else who knows how to deal with it. As, one employee commented: "There was expansion of knowledge involved so that people understand more of the process, not only their little bit." This new mode of working is illustrative of a general trend, evident in the research literature on the finance industry (e.g. Cappelli, 1993; Hunter \& Lafkas, 2003). 
Alongside this new mode of working, the complexity of pension products has grown as a result of increasing government regulation of the financial services industry. For example, there are many regulations concerning the taxable status of payments into or withdrawals from a pension fund, or movements of money between different possible "investment pots" that a customer may have for their pension. These regulations change frequently, and over the 20 to 40-year lifetime of a single pension, many different regulations will attach to money paid into the pension at different times. For Enquiry Team members, the challenge is to be able to organise these details coherently and communicate them to a customer. They also have to be able to judge when it is appropriate to seek the help of colleagues with superior technical knowledge, or to pass enquiries to the various higher technical levels of the organisation.

\section{The annual pension statement: A boundary object?}

In this and the following subsections we present a detailed example of practice at Lifetime Pensions, concerning the annual pension statement. First, we will describe the financial reasoning behind this artefact. Next, we consider some of the mathematical principles that are embedded in the models underlying the statement and the knowledge that Enquiry Team members have of these. Finally, we describe what happens when statements are queried, situations that require negotiation of meanings across boundaries within the company, and the boundary of employee and customer.

The annual statement is a document that is sent annually to every pension holder, with the calculation based on regulations established by the UK Government's Financial Services Authority. Figure 1 shows a sample of one of the simpler types of statement. According to the regulated design of the document, it is supposed to inform customers in a straightforward way about the state of their pension. It is when the statement fails to provide understanding, or leaves the customer needing to know more details, that the work of the Enquiry Team begins. We intend to make explicit the epistemological issues involved in effective communication between customer and Enquiry Team, and between different teams within the company that are drawn into the communication. We also emphasise that what might appear, in this case, to be simple mathematical details, are by no means obvious, even to highly-trained users of mathematics (like ourselves), due to the numerous invisible factors affecting the underlying models. 


$\begin{array}{lccc}\text { Statement date: } 24 \text { April } 2005 & & \\ \text { Date of birth: } 19 \text { April } 1956 & & \text { Pension age: } 60 & \\ \text { Your fund at the statement date is: } & £ 14,223 & & \\ \text { Projected benefits at pension age: } & & \text { Mid rate (7\%) } & \text { Higher rate (9\%) } \\ & \text { Lower rate (5\%) } & £ 28,400 & £ 34,900 \\ \text { At age } 60 \text { your fund would be } & £ 23,100 & £ 1336 \text { pa } & £ 2337 \text { pa } \\ \text { This could buy a pension of } & £ 623 \text { pa } & & \\ \text { OR } & & £ 7,110 & £ 8,720 \\ \text { A tax-free lump sum of } & £ 5,770 & £ 1002 \text { pa } & £ 1753 \text { pa } \\ \text { and a pension of } & £ 467 \text { pa } & \end{array}$

These are only examples and are not guaranteed - they are not minimum or maximum amounts. What you will get back depends on how your investment grows.

FIGURE 1 A simple example of an annual pension statement.

The pension statement shown in Figure 1 represents the simplest case of a fund where no further money is to be invested up to retirement. For each key visible number given, we provide background information to indicate the invisible factors surrounding it. This background data was derived from our earlier ethnographic work listening to customer enquiries and analysing documents.

- The current value of the funds invested (£14,223). Many customers take this to mean that this current fund value is what the pension investment is "worth". This is not necessarily the case. This fact is invisible, and only comes to light if customers ask to transfer their money to a different investment fund (with the same or with a different company), at which point they may discover their investment is worth significantly less - an amount designated as its "transfer value" (see later).

- $\quad$ The projected value of the funds at the point of retirement (e.g., £23,100 at 5\%). Since growth is unpredictable the Financial Services Authority specifies an assumed growth of the funds by compound annual interest rates of 5\% ("lower"), $7 \%$ ("mid") and 9\% ("higher"). What is invisible to many customers is that these rates are set by the financial regulations, corresponding to some reasonable expectations about the future long-term performance of investments. However, we observed that the numbers appeared to some customers to signify a guaranteed investment return. In reality, nothing is guaranteed, as is pointed out in the small print. And in the current financial climate, average returns are actually around 5\% rather than $7 \%$, which leaves the 5-7-9\% range open to further questions.

- The value of the annuity that the projected funds are forecast to buy (i.e., the pension that people will receive annually after retirement; in this case $£ 623$ when using a 5\% projection rate). This amount is calculated as a percentage of the final fund; in reality, but not used in our example, additional and invisible modifying factors are applied to adjust for life expectancies. The mathematics of these 
factors is highly complex, but we noted that the members of the Enquiry Team expressed little appreciation of the relative complexities of the different parts of the statement. All parts were perceived as equally opaque; just numbers in the form of special cases appearing on the computer screen, or a printout whose origins were considered inaccessible.

Another underlying invisible factor (though once again stated in other pension documentation) is that a $0.5 \%$ annual management fee is deducted from each interest rate. For example, the growth at the lower rate (5\%) is actually calculated at $4.5 \%$ per year. Thus even if customers knew how to calculate compound growth, they would not be able to reconstruct the received information using the stated interest rates, unless they had the information about this charge. Moreover, there are still further layers of invisibility, since the $0.5 \%$ figure is only an approximation to the real situation, as customers are subjected to management fees depending on the mixture of their investment funds.

Our own learning process in coming to understand the annual pension statement, along with evidence gathered from analysing customer enquiries, showed that much of the financial and mathematical reasoning behind such an artefact remained hidden to most customers and many employees, even those who were required to communicate with customers. Hence the annual statement emerged as a potential boundary object and an appropriate focus for us, first to characterise the techno-mathematical literacies required to justify the statement, and then to use the statement as a focus for boundary crossing in our subsequent design experiments.

\section{Techno-mathematical literacies for pensions: Compound interest}

As a part of our ethnographic research we talked to members of the Enquiry Team about the type of calculations involved in annual statements. Whilst the detailed models underlying pensions are complex, calculating the projected value from the current fund value requires only the basic concept of compound interest. If we take the lower rate of $5 \%$ and subtract $0.5 \%$ for management charges we obtain a rate of $4.5 \%$, which is transformed to a multiplying factor of 1.045 to allow for easier projecting forwards by 11 years:

$$
14,223 \times(1.045)^{11}=23,081 \quad \text { (rounded to 23,100 in Figure 1). }
$$

At the outset of our research visits, we expected that Enquiry Team members would have some familiarity with this kind of calculation (not least as compound interest is a school mathematics topic), but found in interviews that none of the members of the Enquiry Team were familiar with it, most only vaguely recognising the term "compound interest". This surprised us initially, especially in the case of a trainer with eight years' experience in the company and two industry-standard financial qualifications. We also noted that for some Enquiry Team members, even simple percentages were poorly understood. In such instances, employees' mathematical knowledge can be generally characterised as fragmented, with limited organising theory or appreciation of any structural model. In retrospect, this finding is not so surprising. Even if employees had learned such mathematics at school, they have probably not re-learned it in the context of their work (which is generally a pre-requisite for good understanding), not least because the calculations are deliberately bypassed and delivered by the computer system. From a 
business point of view, this situation may well have been an adequate state of affairs in the past (we were told, "all pension companies have behaved like this"). However, it does not fit with the present, customer-focused way of doing business, and the Enquiry Team members we interviewed all asserted that "better knowledge" would lead to "better communication".

A contrasting example of the power of knowledge in communication was described by an actuary. In meetings with clients, when he needed to make rough calculations in his head, he told us how he employed an approximate formula, the "rule of 70": the time in years (say) to double a fund at interest rate $r \%$ per year is approximately $70 / r$. He commented that clients were often impressed at how he managed to estimate the growth of funds the mental calculation suggested an "air of magic". Of course it is not magic, but it is a question of knowing how to use the right piece of knowledge for the right situation. This, in turn, requires a well-connected knowledge of the underlying models and financial products, and the appropriate use of rules of thumb with recognition of the limits of their validity. (For some further examples of rules of thumb see Noss, Hoyles, \& Pozzi, 2000.)

We emphasise that we do not want to imply that there is a straightforward skills deficit in calculating percentages and compound interest, which could be remedied by focused skills training, or that the skill problem needs to be solved by requiring that all or most enquiry team employees need to be (highly-paid) actuaries. Rather, we want to highlight the epistemological issues that need to be addressed in such customer-oriented situations.

\section{Boundary crossing and the creation of new artefacts}

Having outlined the mathematical models underlying the pension statement and the Enquiry Team's knowledge of them, we now describe the team's work process as a set of boundary-crossing situations that arise as a result of customers' queries about their annual statements. Specifically, we focus on situations where the statement fails to inform customers, and the consequent creation of new artefacts, in this case letters from technical experts, which are meant to support the statement and satisfy the customers' and team's needs.

We begin our analysis with an overview of the workflow. First, the pension statement is sent from Customer Administration to the customer; see Figure 2 (arrow 1). If he or she has a complaint or query, the first point of contact with the company is the Enquiry Team: each of its members will process a number of these enquiries each day (the target is 18), mainly text-based, as noted earlier. The enquiry is expressed as a letter (arrow 2), and the majority of responses will be by letter (arrow 3). In fact, letters become a kind of "unit of communication": the Enquiry Team members often expressed themselves in the form "we [don't] have a letter for that", that is, a standard letter exists to respond to the enquiry (or not). Letters may be official texts passed to the Enquiry Team from other areas of the company (e.g., product development or marketing), or locally-produced texts which the Enquiry Team members maintain in their own "library".

Lifetime Pensions expects that the training provided for members of the Enquiry Team is sufficient to prepare them to answer customers' questions at a general level. For enquiries that the Enquiry Team find too "technical" to deal with (about 20\%), there is a system of technical experts in place. The first port of call for a technical enquiry (arrow 4) is an 
actuarial assistant, who is a mathematics graduate, but not formally educated in financial services. The second port of call is an actuary, with more than 30 years' experience in financial product and service development, and who has now moved to a back-office role as an adviser to customer enquiries. The actuary and assistant write "technical notes" (arrow 5) for issues that arise frequently, which are meant to explain the issues to the Enquiry Team as well as to the customer. They also write paragraphs or pages of explanatory text that Enquiry Team members can insert into or append to their letters to customers. These texts range from answers to the specific situation of the customer (for example, see Figure 3 below), to general descriptions and hypothetical examples.

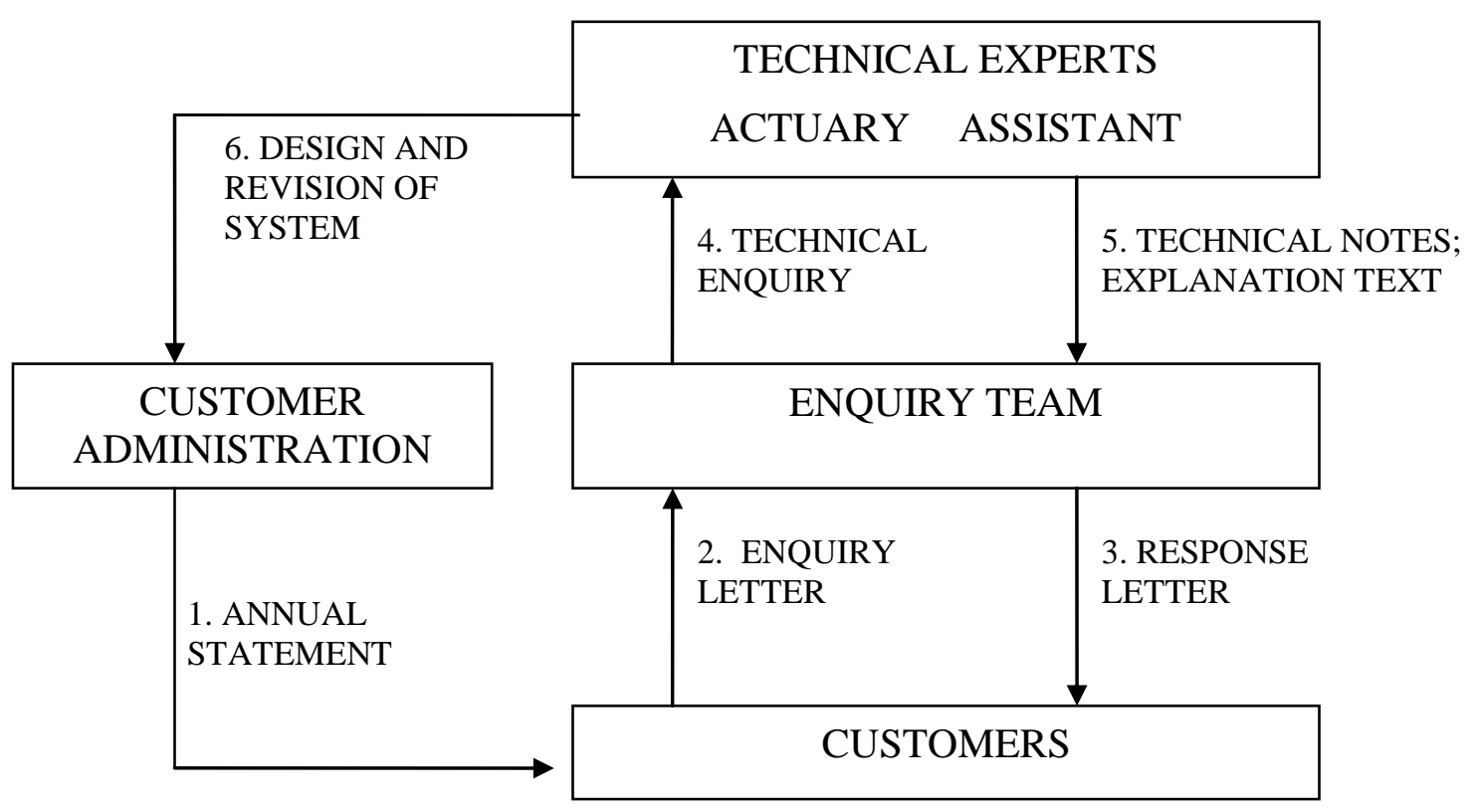

FIGURE 2 Boundary crossing situations in the Lifetime Pensions' system for dealing with customer enquiries. Note that Interactions 2 and 3 are becoming increasingly telephone-based rather than text-based.

The scope for customer queries concerning the annual statement occurs on several levels. At a basic level, there are some customers who believe that the stated growth of their funds is guaranteed, like a bank savings account, and so they may not understand why three different interest rates are used. They may compare the latest and previous annual statements, or query why the actual growth of their investment (which can indeed be an actual reduction in value) does not match any of the given interest rates. The majority of customers do recognise that the growth rates given are essentially hypothetical but nonetheless query which rate and final amount of money they can expect to receive. Thus, they do not realise that expected growth rates are specified by the financial regulations, rather than by Lifetime Pensions. 
Some customers demand a detailed ad hoc explanation of their individual case. They may query the management charges and other deductions applied to their fund, sometimes sending in their own detailed set of calculations to support their argument. Indeed, as already described, this situation is not simple, since the charges depend on the precise pension product involved, and are invisible in the statement. This kind of query is typically one that must be referred to the actuary or actuarial assistant, since it requires knowledge of the mathematically-based model underlying the pension. The Enquiry Team members reported that they found queries of this type to be the most problematic. Yet some of these queries could be relatively straightforward for someone with a better partial knowledge of the underlying models: for example, customers who project their fund value to retirement using a 5\% rate may ask why their figure is higher than the figure on the statement. In this case, the answer is simple: due to the (non-obvious) management charge of $0.5 \%$ per annum the projection is actually calculated using $4.5 \%$ instead of $5 \%$.

In rare cases, customers point to an incorrect calculation in their statement which is a result of "bugs" in the Lifetime Pensions computer systems. These bugs must be identified and acted on as quickly as possible as they could be very expensive to the company if they involved the need for financial compensation to current or previous customers. In such cases, the technical experts have to collaborate with actuaries to find the mistakes in the computer systems and to correct them (arrow 6 in Figure 2).

\section{An explanation of transfer values}

We give one, more elaborate, example related to a customer query about the current value of their fund. As mentioned earlier, customers often assume that the current fund value stated on their annual statement is what their fund is worth; yet, if customers want to transfer their pension fund to another pension scheme, they often discover that the transfer value - the money they can take away - is less than their current fund value. Customers generally interpret this as either a penalty or even that the company is just holding on to some of their money. We give an example of just such a query. A customer wanted to know why her transfer value $(£ 10,001)$ was less than the current fund value $(£ 10,924)$. The Enquiry Team passed the query on to the actuary, who prepared a 2-page explanation text of this particular case of which we cite a fragment in Figure 3. Before we discuss the details of this case, we explain the underlying situation in general terms.

We learnt from the actuary that the underlying mathematical reason behind the difference between a current fund value and a transfer value is that the fund value at retirement has to be the same for each pension scheme, but that different charges might be applied to arrive at that value. The current fund value is therefore projected forwards to the customer's retirement age, using an assumed interest rate minus the management charges for the present pension scheme. That projected value is then translated backwards to the current date with the (in this case) lower charges of the new pension scheme. This results in a value at the current date lower than the current fund value, although the (estimated) value at retirement will be the same.

When a query regarding transfer values comes to a member of the Enquiry Team, he or she refers it immediately to a technical expert, who prepares a document to explain the customer's case in considerable detail, as in Figure 3. This explanatory document is 
written to serve as a supporting artefact to the annual statement and transfer value quotation. However, we found that Enquiry Team members generally could not understand these explanatory texts, and could not therefore adapt them for use in similar cases. This is inefficient: the (expensive) actuary has to tailor-make answers to questions from individual customers that are, in fact, structurally similar. But they have to do this as there is the need for objective mathematical explanations if customers are to understand what the company is doing and to allay any suspicions that they are being cheated.

The full explanation text, of which Figure 3 is an excerpt, has 26 points in all and explains that starting from the transfer value of $£ 10,001$ the customer should arrive at the same value at retirement as when starting with $£ 10,924$ of the present pension plan. Each step of the calculation is given, in order to show that "the transfer value of $£ 10,001$ was fair value". Once we understood the mathematical structure underlying this argument, we were convinced of the "fair value", although what is invisible to the customer, even in this text, is that the costs for the company of setting up the first pension scheme and the commission paid to intermediary sales advisors have been spread over the whole lifetime of the pension scheme as a management charge, and it is mainly the company's taking back of all these charges which leads to the lower transfer value.

8. The difference of $£ 923$ between the fund value of $£ 10,924$ and the transfer value of $£ 10,001$ is often called a charge (and sometimes a penalty). We do not believe either of these phrases is appropriate, as I will now show.

9. The primary purpose of a pension plan is to provide on retirement - which was 27 May 2015 under your [pension] plan. So let us see what might happen to the Initial and Accumulation Units if they were to be maintained until May 2015.

10. Firstly consider what would happen to the $£ 8,317$ of Accumulation Units on 8 June 2004.

11. They will grow for another 11 years (until May 2015).

12. To carry out the calculation we need to make an assumption about investment returns over that period of 11 years. For the purposes of this illustration let us assume that, before any charges are deducted, the investments grow at $7 \%$ pa.

13. Then the Accumulation Unit fund would, by May 2015, have grown to: $8,317 \times(1.07)$ to the power of $11 \times(4798 / 4800)$ to the power of 132 i.e. 16,569

The factor of $(4798 / 4800)$ is derived directly from the monthly charge discussed in section 5 of this note $[2 / 48 \%$ per month].

FIGURE 3 Part of an explanation text prepared by the actuary as a response to a transfer value enquiry.

The example queries we noted in our research demonstrated a need for members of the Enquiry Team to understand the structural direction of the explanatory letters that pass between Enquiry Team and actuary/assistant (arrows 4 and 5, Figure 2), and between Enquiry Team and customer (arrows 2 and 3). This is especially true if they have to decide if a letter from their library is useful for answering a new query about a similar issue. Could they adapt it to fit the new situation? The actuary expressed two concerns 
about this. First, he wondered how well these adaptations were made. Second, he remarked that all too frequently he was asked to answer queries that, in his eyes, the Enquiry Team members could have dealt with themselves. In his view, the Enquiry Team "is an area where people would feel more confident if they could see how things are calculated." Indeed, many Enquiry Team members expressed just this wish: to know more about the calculations carried out "behind the screen". Confidence was a major concern to the managers we met, and from our interviews and questionnaires we concluded that it was a widely accepted view that better understanding of the mathematics behind financial calculations would benefit confidence, and also improve explanatory interactions with customers.

Our observations of practice in the Enquiry Team showed a need for some appreciation of the mathematical models underlying pension statements, and the invisible factors which determine the contents of the statement. Without the support of technomathematical literacies, Enquiry Team members have a limited capacity to deal directly with customer queries, or to learn from the extensive input of technical experts, and to adapt or use their texts effectively. Even when an Enquiry Team member could understand a particular text, our impression was that this did not readily develop into being able to generalise to cases of the same or a similar enquiry. Each enquiry was seen as a new case, rather than as an instance of a more general situation governed by essentially the same (mathematical) model.

\section{Discussion}

The central question underlying the ethnographic phase of our research into technomathematical literacies in the workplace has been how to characterise the use of mathematical knowledge at work. This question is particularly relevant in the light of two major changes in the workplace: the computerisation of workplaces and the shift to more customer-focused operations. In order to characterise our idea of techno-mathematical literacies we have described the new modes of work required in one financial services company, in particular in the Enquiry Team that operates at the interface between customers and experts in dealing with technical enquiries. We focused on this team because their need for techno-mathematical literacies was most evident, in contrast with other areas where the work processes were well-defined, and calculations were outsourced to the IT system, with little need for communication and judgement.

We have elaborated our theoretical position on boundary objects and boundary crossing and have stressed the former's epistemological nature and flexible character; a boundary object must facilitate the articulation and communication of different meanings from different communities. We noted that the company's annual pension statement was intended to serve as a boundary object between customer and company but frequently did not do so by itself, generating the need for explanations from the Enquiry Team, often augmented by texts prepared by technical experts. However, for these communications to be successful, we have shown how underlying models need to be appreciated and various invisible factors recognised. The ideas underlying these models range from relatively simple ideas such as compound interest, to the more complex financial notions of transfer values and annuities. It was significant that members of the Enquiry Team did not distinguish the relative complexity of these models, but found the workings of all of them 
equally opaque. This is in part the result of an intentional strategy of technologising of the workplace through automation of the IT system, rather than "information" of the employees. In a drive to ensure the accuracy of information sent to customers, "automations" have been added to the IT system to provide button-press answers for certain procedures and calculations. As these automations have accumulated over time, the separation of the employee from knowledge of the underlying system has increased, progressively disempowering the employee, and separating him or her, not only from any understanding of the models and calculations, but also from being able to communicate about these with colleagues and customers. When, as in the case of Lifetime Pensions, the working practices of a company shift from a long-running development based on productivity to a focus on flexible response to customer needs, we see the longbackgrounded "knowledge gap" around mathematical models of the financial products and IT systems emerge into the foreground.

The assumption that mathematics can be embedded in the computer system, and be of concern only to technical specialists, leads to a neglect of techno-mathematical knowledge which is compounded, in many industrial sectors, by a general pattern of mathematics avoidance running through working practices. Mathematics is a problem subject, which often frightens and alienates employees, so that the mathematical aspects of products are often intentionally avoided in initial training and continuing development for employees. Thus we observe that companies are re-organising to deal with changing circumstances, such as expanding their capacity to explain themselves to customers, but they do so in ways that attempt to adapt the existing, usually limited, mathematical practices, rather than seeking deeper changes to the mathematical knowledge basis of work. In this paper, we have identified the need for employees to understand what lies behind the symbols that appear on their screens, to the extent that they can either answer a customer directly or know how to refer the question to an expert, or recognise that they can adapt an existing solution to fit this particular case. In all these cases, the meanings of the symbols in the specific case have to be reconciled with their meanings in the general case, and ways found to communicate this. We found in general that employees lacked this language of description for the techno-mathematical literacies required.

We also observe that a language of description was lacking amongst employers. Thus the notion of techno-mathematical literacies itself has been a boundary object in our conversations with employers: in most companies we have found the need to negotiate what is the nature of the "skills gap" that we and they perceive. Some companies in our research - particularly those in the financial sector - do recognise that there is a gap to be addressed, but even so, do not find it easy to conceptualise this within their current ideas about "mathematical skills". We should emphasise that we are not advocating any simple "refreshing" of school mathematics knowledge. Rather we advocate a move to a modelbased appreciation and its articulation in the context of boundary crossing, where the negotiation of meanings takes place.

We give two reasons for this conviction, one concerning the central place of work context and the other of tool mediation. With respect to the former, our case studies have highlighted the differences between workplace mathematics and school mathematics. The mathematics involved in finance seems superficially to be similar to what appears in the secondary school mathematics curriculum (for example, calculating compound interest). 
Yet the effect of workplace context is to introduce a significant degree of complexity to even the simplest mathematics. Any mathematical procedure is not an isolated exercise but is part of a set of decisions and judgements that have to be made about what is a complex process or product. In Lifetime Pensions, the actuarial assistant phrased it thus: "The maths involved is not hard, but it is applied in a very complicated way - there are the company rules and Inland Revenue [tax] rules". It is this complexity that is generally invisible and needs to be articulated so that in some cases at least, the calculations will become less problematic.

More generally, Steen (2003, p.55) writes that "Mathematics in the workplace makes sophisticated use of elementary mathematics rather than, as in the classroom, elementary use of sophisticated mathematics". In school situations, as Van Oers (1998) observes, context can bring coherence to the learning of mathematics. In workplace situations such as we have described, we argue that the reverse situation exists- that an understanding of mathematical models can bring coherence to employees' contexts and can improve their chances of communicating the information derived from artefacts, such as the pension statements, effectively and efficiently. Employees have to relate the general model to the specifics of the customer's situation: that is to "web" mathematical and contextual knowledge, producing meaning in their activity by coordinating both knowledge forms (Noss \& Hoyles, 1996b).

The second reason for advocating a model-based approach to mathematics in the workplace is that nowadays employees almost invariably work with computer outputs, rather than pen and paper; what they need are techno-mathematical literacies that are mediated by the technology present in workplaces. They need to be able to appreciate the computer outputs from a mathematical perspective while interpreting them in their context and recognising the parts that the IT system has kept hidden. The case study shows the importance of reasoning about the models embedded in the IT system, in terms of the key relationships between product "variables" (percentage rates, management fees, sales commissions, etc.) and their effect on "outputs" that are visible to the customer (fund value and transfer value, projections for estimated values at retirement, etc.).

In the second phase of our research we have found that the development of technomathematical literacies can be facilitated by designing boundary-crossing situations around mathematical artefacts used at work, such as the pension statement. In our experience, spreadsheet software is an effective tool for this type of exploration of models, since it can be used to make visible the key mathematical structures and relationships underlying the familiar artefact, with employees being guided to construct the calculations for themselves and encouraged to formulate explanations on the basis of their constructions (see Bakker et al., 2006).

The need for techno-mathematical knowledge and model-based understanding is not specific to the financial sector. For example, in pharmaceutical companies, whose practices are highly regulated, there are written regulations which prescribe how work tasks are to be done (standard operating procedures or SOPs). One example that struck us concerned rounding numbers, that is, how to round figures to a particular number of decimal places. Operators are required to know the regulated procedures so that drugs are correctly manufactured, but because many of the procedures are formulated in rather formal language, they do not serve as boundary objects, and additional training materials 
have to be developed to assist employees in making sense of the SOPs. In this case, as much as in the pensions statement, the object does not achieve its communicative potential because its central epistemological dimension is ignored in favour of opaque, routinised procedures.

It is the need and development of disciplinary knowledge as mediated by technology at work, that is, in our view, downplayed in many activity-theoretical studies. For example, in Engeström's work $(1999,2001)$, boundary objects are mostly artefacts that collaborating groups of professionals agree to use to interrogate and change their work practice. His Boundary Crossing Laboratory is thus set up to facilitate a reorganisation of work. In our example, the central boundary object was an artefact that was initially issued as a summative statement, and only converted into an actual boundary object when customers queried it. The purpose, in this case, was not to reorganise work, but to satisfy customers' and team members' needs for information and understanding.

We end by reiterating our primary goals: to identify the techno-mathematical literacies used or needed by employees in current, technology-rich workplaces, and to develop theoretical ideas which complement the research of others (such as Derry, 2003; Guile, in press) in seeking to conceptualise a crucial role for knowledge within activity theory. We have used activity theory in ways somewhat divergent from (for example) Engeström's conception, by adding an epistemological dimension to the concepts of "object of activity" and "activity system". This has allowed us to characterise the technomathematical literacies at stake if companies are to meet their espoused goals of having a workforce that is capable of offering informative and responsive communication with customers.

\section{Acknowledgements}

We would like to thank the two reviewers of this paper for their helpful comments. This research is supported by the United Kingdom Economic and Social Research Council, Teaching and Learning Research Programme [www.tlrp.org], Award Number L139-250119, as part of the "Techno-mathematical Literacies in the Workplace" project.

\section{References}

Bakker, A., Kent, P., Noss, R., Hoyles, C., \& Bhinder, C. (2006). "It's not just magic!" Learning opportunities with spreadsheets for the financial sector. Proceedings of the Day Conference of the British Society for Research into Learning Mathematics, February 2006.

Bowker, G. C., \& Star, S. L. (1999). Sorting things out. Classification and its consequences. Cambridge, MA: MIT Press.

Cappelli, P. (1993). Are skill requirements rising? Evidence from production and clerical jobs. Industrial and Labor Relations Review, 46(3), 515-530.

Cobb, P., Confrey, J., diSessa, A. A., Lehrer, R., \& Schauble, L. (2003). Design experiments in educational research. Educational Researcher, 32, 9-13. 
Coben, D. (2003). Adult numeracy: Review of research and related literature. London: National Research and Development Centre for Adult Literacy and Numeracy.

Coben, D. (in press). The social-cultural approach to adult numeracy: Issues for policy and practice. In L. Tett, M. Hamilton, Y. Hillier (Eds.), Adult literacy, numeracy and language: Policy, practice and research. Buckingham: Open University Press.

Derry, J. (2003). Vygotsky and his critics: Philosophy and rationality. Unpublished PhD thesis, University of London, London.

Engeström, Y. (1999). Expansive visibilisation of work: An activity-theoretical perspective. Computer Supported Cooperative Work, 8, 63-93.

Engeström, Y. (2001). Expansive learning at work: Toward an activity theoretical reconceptualization. Journal of Education and Work, 14(1), 133-156.

Felstead, A., Gallie, D., \& Green, F. (2002). Work skills in Britain 1986-2001. London: Department for Education and Skills.

Fitzsimons, G. E. (2002). What counts as mathematics: Technologies of power in adult and vocational education. Dordrecht: Kluwer Academic.

Fitzsimons, G. E., Coben, D., \& O'Donaghue, J. (2003). Lifelong mathematics education. In A. J. Bishop, M. A. Clements, C. Keitel, J. Kilpatrick, \& F. K. S. Leung, Second International Handbook of Mathematics Education (Volume One, pp. 103 -142). Dordrecht: Kluwer Academic Publishers.

Guile, D. (2006). What 'knowledge' in the knowledge economy? Implications for education. In A. A. Halsey, P. Brown, \& H. Lauder (Eds.), Education, Culture and the Economy. Oxford: Oxford University Press.

Guile, D. (in press). The learning challenge of the knowledge economy. Rotterdam: Sense Publishers.

Guile, D., \& Young, M. (2003). Transfer and transition in vocational education: Some theoretical perspectives. In T. Tuomi-Gröhn \& Y. Engeström (Eds.), School and work: New perspectives on transfer and boundary-crossing (pp. 63-84). Amsterdam: Pergamon.

Hoyles, C., Bakker, A., Kent, P., \& Noss, R. (8 January, 2006). Attributing meanings to representations of data: The case of statistical process control. Manuscript submitted for publication.

Hoyles, C., Wolf, A., Molyneux-Hodgson, S. and Kent, P. (2002). Mathematical skills in the workplace. London: The Science, Technology and Mathematics Council. Retrieved 23 May 2006 from http://www.ioe.ac.uk/tlrp/technomaths/skills2002 .

Hunter, L. W., \& Lafkas, J. L. (2003). Opening the box: Information technology, work practices, and wages. Industrial and Labor Relations Review, 56(2), 224-243.

Kaptelinin, V., \& Miettinen, R. (Eds.). (2005). Perspectives on the object of activity [Special issue]. Mind, Culture, and Activity, 12(1). 
Kent, P., \& Noss, R. (2000). The visibility of models: Using technology as a bridge between mathematics and engineering. International Journal of Mathematical Education in Science and Technology, 31(1), 61-69.

Kim, Y.-H. (2002). A state of the art review on the impact of technology on skill demand in OECD countries. Journal of Education and Work, 15(1), 89-109.

Kuutti, K. (1996). Activity theory as a potential framework for human-computer interaction research. In B.Nardi (Ed.), Context and consciousness: Activity theory and human-computer interaction (pp. 17-44). MIT Press.

Noss, R. (1998). New numeracies for a technological culture. For the Learning of Mathematics, 18(2), 2-12.

Noss, R., \& Hoyles, C. (1996a). The visibility of meanings: Modelling the mathematics of banking. International Journal of Computers for Mathematical Learning, 1(1), 331.

Noss, R., \& Hoyles, C. (1996b). Windows on mathematical meanings: Learning cultures and computers. Dordrecht, the Netherlands: Kluwer Academic Publishers.

Noss, R., Hoyles C. \& Pozzi S. (2000). Working knowledge: Mathematics in use. In A. Bessot, and J. Ridgway (Eds.), Education for Mathematics in the Workplace (pp. 1735). Dordrecht, the Netherlands: Kluwer Academic Publishers.

OECD. (2003). PISA 2003 assessment framework. Paris: Organization for Economic Cooperation and Development.

Rothwell, W. J., \& Lindholm, J. E. (1999). Competency identification, modelling and assessment in the USA. International Journal of Education and Training, 3, 90-105.

Russell, D. R. (2002). Looking beyond the interface: Activity theory and distributed learning. In M. R. Lea, \& K. Nicoll (Eds.), Distributed learning: Social and cultural approaches to practice (pp. 64 - 82). London: Routledge Falmer.

Star, S. L., \& Griesemer, J. (1989). Institutional ecology, 'translations,' and boundary objects: Amateurs and professionals in Berkeley's Museum of Vertebrate Zoology, 1907-1939. Social Studies of Science, 19, 387-420.

Steen, L. A. (2003). Data, shapes, symbols: Achieving balance in school mathematics. In B. L. Madison \& L. A. Steen (Eds.), Quantitative literacy: Why literacy matters for schools and colleges (pp. 53-74). Washington, DC: The Mathematical Assiociation of America. Retrieved 23 May 2006 from http://www.maa.org/ql/qltoc.html .

Tuomi-Gröhn, T., \& Engeström, Y. (Eds.). (2003). Between school and work: New perspectives on transfer and boundary-crossing. Amsterdam: Pergamon.

Van Oers, B. (1998). From context to contextualising. Learning and Instruction, 8, 473488.

Victor, B., \& Boynton, A. C. (1998). Invented here: Maximizing your organization's internal growth and profitability. Boston: Harvard Business School Press.

Wake, G. (2005). Functional mathematics: More than "Back to Basics". Nuffield Review of 14-19 Education and Training. Aims, Learning and Curriculum Series, Discussion 
Paper 17. Oxford: Department of Educational Studies, University of Oxford. http://www.nuffield14-19review.org.uk/files/documents101-1.pdf.

Wenger, R. H. (1998). Communities of practice: Learning, meaning, and identity. New York: Cambridge University Press.

Zuboff, S. (1988). In the age of the smart machine: The future of work and power. New York: Basic Books. 